\title{
Ophthalmology specialist trainee survey in the United Kingdom
}

\author{
William H. Dean ${ }^{1,2} \cdot$ Susannah Grant ${ }^{3,4} \cdot \operatorname{Jim}$ McHugh $^{5} \cdot$ Oliver Bowes $^{6} \cdot$ Fiona Spencer $^{3,7}$
}

Received: 3 July 2018 / Revised: 14 November 2018 / Accepted: 21 December 2018 / Published online: 1 February 2019

(c) The Royal College of Ophthalmologists 2019

\begin{abstract}
Background Currently there are a total of 780 post-graduate ophthalmology trainees in the United Kingdom (UK). Postgraduate ophthalmology training in the UK is 7 years in duration, and follows a comprehensive competency-based curriculum. Changes to training have been proposed as part of the government's Shape of Training paper.

Methods UK ophthalmic trainees and trainers, in partnership with the Royal College of Ophthalmologists, designed a national questionnaire to explore the confidence of trainees in different clinical and non-clinical aspects of ophthalmology. The questions and possible responses underwent a process of refinement through the Royal College of Ophthalmologists Training Committee and Trainee Group. An online survey platform was used for the questionnaire, which was sent to all ophthalmology trainees within the UK. Reminders were sent via the Royal College of Ophthalmologists and Regional Training Programme Directors. A 4-week period was allowed for responses. Quantitative data were analysed, and qualitative data analysis included collation and thematisation of free-text responses.

Results A total of 188 trainees (24.1\% response rate) replied. Ninety-four percent of trainees were in full-time training posts. The most popular career choice was oculoplastics (31.4\%), followed by vitreo-retina (25.1\%), glaucoma (24.6\%) and cornea $(24.0 \%)$. One-quarter had opted out of the European working time directive (EWTD), and $54.8 \%$ agreed that their work contract reflected the number of hours actually worked. In total, $34.4 \%$ of trainees thought that ophthalmic specialist training should be shortened from the current 7-year programme. Overall, $79.9 \%$ of respondents felt confident in performing phacoemulsification cataract surgery independently. For more senior trainees in years 4-7, 100\% felt confident in phacoemulsification. However, overall, only $47.9 \%$ were confident in independently performing an anterior vitrectomy $(91.1 \%$ of final-year trainees). Overall, $77.6 \%$ thought that all surgical ophthalmologists should be trained to perform cataract surgery. For non-clinical skills, trainees felt least confident in 'preparing a business case', with $64.5 \%$ disagreeing that they felt confident in this task. The most confidence was felt for communication with patients: $100 \%$ of trainees (all of whom have completed at least 2 years of medical work following qualification) reported feeling confident.

Conclusions Most doctors in post-graduate specialist training in ophthalmology in the UK aim to specialise in surgical subspecialities. The subjective reports collected in this survey suggest targets for strengthening of the UK's highly rated training system. Further research is necessary to determine overall satisfaction with training, the effect of changing training within the recent Shape of Training review; and how recent newly imposed junior doctor contracts as well as Brexit affects training.
\end{abstract}

William H. Dean

will.dean@1shtm.ac.uk

1 International Centre for Eye Health, London School of Hygiene and Topical Medicine, London, UK

2 Community Eye Health Institute, University of Cape Town, Groote Schuur Hospital, Cape Town, South Africa

3 The Royal College of Ophthalmologists, London, UK
4 The Royal College of Emergency Medicine, London, UK

5 Department of Neuro-Ophthalmology, National Hospital for Neurology and Neurosurgery, University College London Hospital NHS Trust, London, UK

6 Department of Ophthalmology, Cambridge University Hospitals NHS Foundation Trust, Cambridge, UK

7 Manchester University NHS Foundation Trust, Manchester, UK 


\section{Introduction}

There are 2880 ophthalmologists for the 65 million population of the UK, a ratio of 44 per million [1]. Ophthalmology is a popular speciality for training, with a mean competition ratio of around four applications per post advertised [2].

Ophthalmology specialist training (OST) undertaken full-time in the UK lasts 7 years, the longest in the world. The UK has been one of the first countries to fully embrace a competency-based curriculum. It mandates the greatest number of surgical procedures and the greatest number of objective competency assessments of surgical and procedural skills. UK ophthalmology training is rated highly, with an overall satisfaction rating of $83.5 \%$ [3].

The European Working Time Directive (EWTD), limiting the hours worked per week, was extended to cover junior doctors in the UK in 2004. By 2009, the working week for junior doctors had been reduced through the EWTD to a mean of $48 \mathrm{~h}$ (averaged over 6 months). It remains to be seen how Brexit (departure of the UK from the European Union) will affect this [4, 5]. This limit of working time is reported to have decreased the total surgical training time available for trainees in the UK.

Modernising Medical Careers (MMC) was a UK policy introduced in 2005. It shortened training duration, introducing a 'run-through' training (i.e., the abolition of competitive application for limited posts between basic and higher ophthalmic training), and made changes of specialty problematic [6, 7].

The Shape of Training review was published in 2013 [8]. It broadly aims to further shorten training, create more 'generalists', and increase flexibility of training. It has recently been adopted by the four UK Departments of Health.

With the first graduates of the complete 7-year MMC run-through training having recently completed training, we designed a survey of UK ophthalmology specialist trainees to gain their views about their confidence in various clinical and non-clinical aspects of the role of a fully trained UK ophthalmologist.

There have been a number of ophthalmologist training surveys, including the USA [9, 10], Canada [11], Nigeria [12], Jordan [13], India [14] and China [15]. National surveys of this kind are widely accepted research tools.

\section{Methods}

A questionnaire was designed by a panel of trainee and expert trainer ophthalmologists in the UK, in partnership with education staff of The Royal College of Ophthalmologists. The questions and possible responses underwent an iterative process of refinement.
A web-based SurveyMonkey platform (San Mateo, CA, USA) was used for the questionnaire. The questionnaire was sent electronically to all ophthalmology trainees within the UK. Reminders were sent via Regional Training Programme Directors.

Responses were collated and analysed. Further qualitative data analysis included collation and thematisation of responses was conducted where appropriate.

The minimum sample size was calculated from a total population of 780 , with a confidence level of $95 \%$ and margin of error of $10 \%$, to be 86 . This figure was calculated using the SurveyMonkey online calculator algorithm.

\section{Results}

A total of 188 trainees replied ( $24.1 \%$ response rate). This is more than double the minimum sample size needed, and the rate is considered good for an external, online survey. Although it may be a source of ascertainment bias, it is a higher rate than the $4.4 \%(87 / 2000)$ in the US survey [9], and comparable with the Canadian survey 40/99 (40\%) [11]. It is a lower rate than the internal survey in India (107/ $155,69 \%$ ), however, it should be noted that this survey was conducted at an intensive teaching programme, and therefore prone to selection bias [14].

There was an even spread of responses from years 1 through 7. The largest number of responses were from the London, Yorkshire and Humber, Severn (South West) and West Midlands Deaneries (17.6\%, 9.6\%, 8.0\% and 8.0\%, respectively). Responses were received from all Deaneries in the four UK countries.

Most respondents (88.3\%) were in General Medical Council (GMC) accredited OST posts. Overall, $6.4 \%$ were in academic training posts. Overall, $23.4 \%$ were in the first 2 years of training, $25.4 \%$ in years 3 and 4 , and $44.8 \%$ in the final 3 years of training.

The majority of trainees (94.1\%) were in full-time training. Within this current survey, one quarter $(24.5 \%)$ stated they had opted out of the EWTD.

When asked, 'does your contract reflect the number of hours you actually work?': $54.8 \%$ agreed and 33.5\% disagreed.

Overall, $34.4 \%$ of trainees thought that OST should be shortened from the current 7-year course. This increased to $44.8 \%$ when asked: "Do you think training could be shortened, and still produce competent consultant ophthalmologists?"

\section{Career preferences}

Career preferences and/or aspirations were recorded, and participants were invited to select all responses that were 
appropriate. The most common were oculoplastics (31.4\%), vitreo-retinal $(25.1 \%)$, glaucoma $(24.6 \%)$ and cornea (24.0\%) (see Table 1).

Initial qualitative thematic analysis of responses showed the most common reason stated for career preference was clinical interest $(37.6 \%)$ followed by surgical interest (27.1\%). Enjoyment was mentioned by $15.0 \%$, job opportunities by $11.3 \%$ and $10.5 \%$ stated previous experience. Only one respondent volunteered 'availability of private practice' as a reason for career choice/aspiration (within the 'other' response).

Further direct, specific and graded questions illustrated that clinical interest $(91 \%)$ remained the most important factor, and private practice opportunities the least $(22 \%)$ important influencing career decisions.

\section{Clinical skills and clinical confidence}

By the end of the 7-year training programme, all trainees will have covered a range of sub-specialities. For all respondents across all years, most clinical confidence was felt in cataract $(87.6 \%)$, glaucoma $(78.7 \%)$ and medical retina $(75.8 \%)$. Overall, only $32.5 \%$ felt confident in clinical areas of ocular oncology, and $48.5 \%$ in low-vision.

Per-year analysis of confidence in more medically orientated clinical sub-speciality areas is illustrated in Fig. 1a. There is a steady increase in most areas, with most confidence being felt by final-year trainees in medical retina (97.1\% confident) and uveitis $(94.1 \%)$. Least clinical confidence (from $0 \%$ in years 1 and 2 , to $70.1 \%$ in final year) was in ocular oncology.

Table 1 Current career preference/aspiration

At this time, what is your career preference/aspiration? (please tick all that apply)

\begin{tabular}{lll}
\hline Answer options & Response percent & Response count \\
\hline Oculoplastics & $31.4 \%$ & 55 \\
Vitreo-retinal & $25.1 \%$ & 44 \\
Glaucoma & $24.6 \%$ & 43 \\
Cornea & $24.0 \%$ & 42 \\
Medical retina & $18.9 \%$ & 33 \\
General & $17.7 \%$ & 31 \\
Paediatrics \& strabismus & $14.9 \%$ & 26 \\
Research/academic & $13.1 \%$ & 23 \\
Primary care/accident \& & $9.1 \%$ & 16 \\
emergency & & \\
Neuro-ophthalmology & $8.0 \%$ & 14 \\
Medical ophthalmology & $2.3 \%$ & 4 \\
Global health & $2.3 \%$ & 4 \\
Other & & 5 \\
\hline
\end{tabular}

Per-year analysis of confidence in more surgically orientated clinical sub-speciality areas is illustrated in Fig. 1b. Again, there is a steady increase in most areas, with a noticeable exception in cataract, whereby year-4 onwards, $100 \%$ feel confident.

\section{Surgery and surgical confidence}

In response to the question 'Should all surgical ophthalmologists be trained to perform cataract surgery?', 77.6\% stated yes, $15.5 \%$ stated no and $6.9 \%$ were unsure.

Figure 2 illustrates surgical confidence for all years, and by year. The majority of all trainees, $79.9 \%$, felt confident in performing phacoemulsification cataract surgery independently. Sub-group analysis showed that $40.9 \%$ of more junior trainees (ST1 to ST3) did not feel confident performing phacoemulsification; however, $100 \%$ of ST4-7 trainees agreed that they were confident in performing phacoemulsification independently.

Overall, $47.9 \%$ of respondents were confident in performing an anterior vitrectomy. Sub-group analysis of anterior vitrectomy (OST1-3 and OST 4-7) illustrated that $83.1 \%$ of ST1-3 year trainees did not feel confident in performing anterior vitrectomy, however, $74.4 \%$ of more senior trainees in years 4-7 did feel confident in independently performing an anterior vitrectomy.

\section{Non-clinical skills}

Trainees felt least confident in 'preparing a business case', with $64.5 \%$ disagreeing that they felt confident in this task, and only $20.1 \%$ agreeing they felt confident (Fig. 3).

The most confidence was felt for communication skills. $100 \%$ of trainees felt confident in communication with patients, and $99.4 \%$ were confident in communication with colleagues.

\section{Discussion}

Ophthalmology training in the UK is the longest in the world at 7 years, with widely accepted excellence in surgical training opportunities. There have been important national changes in medical training in the past decade, and this is the first survey of ophthalmology trainees since the first completed cycle of the 'run-through' 7-year ophthalmology specialist training (OST).

When asked about career preferences, the most common were surgically orientated: oculoplastics (31.4\%), vitreoretinal $(25.1 \%)$, glaucoma $(24.6 \%)$ and cornea $(24.0 \%)$. These stated career aspirations, however, may not match the availability of recent substantive Consultant Ophthalmologist posts in the UK [16]. Consultant posts advertised in the 
Fig. 1 a Medical ophthalmology Surgically oriented clinical confidence by year clinical confidence by year. b

\section{a}

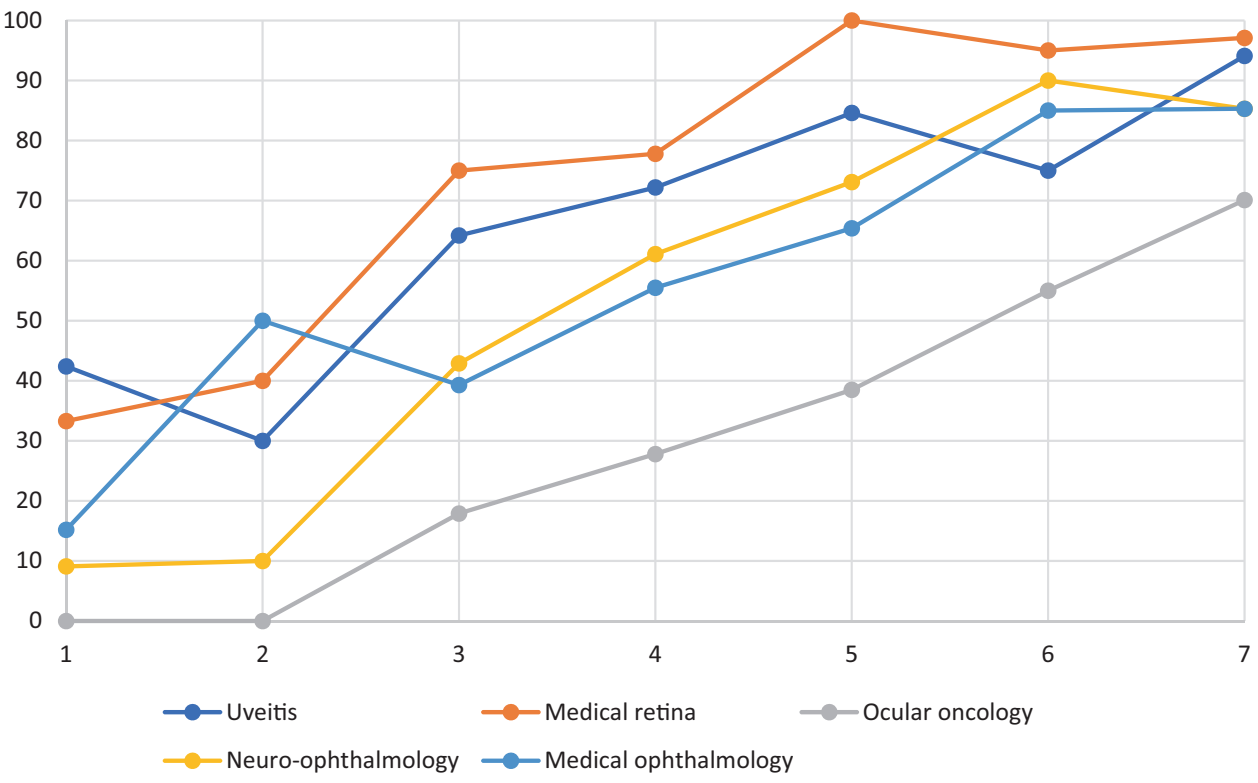

b Yearly Confidence Percentage

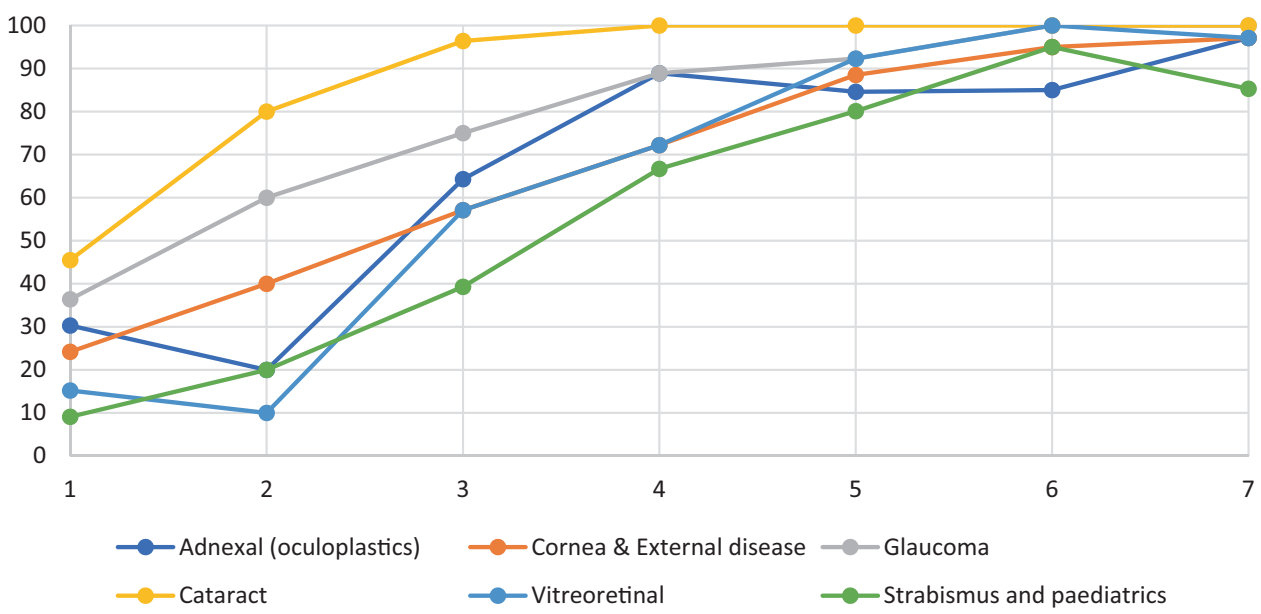

Fig. 2 Surgical confidence by year

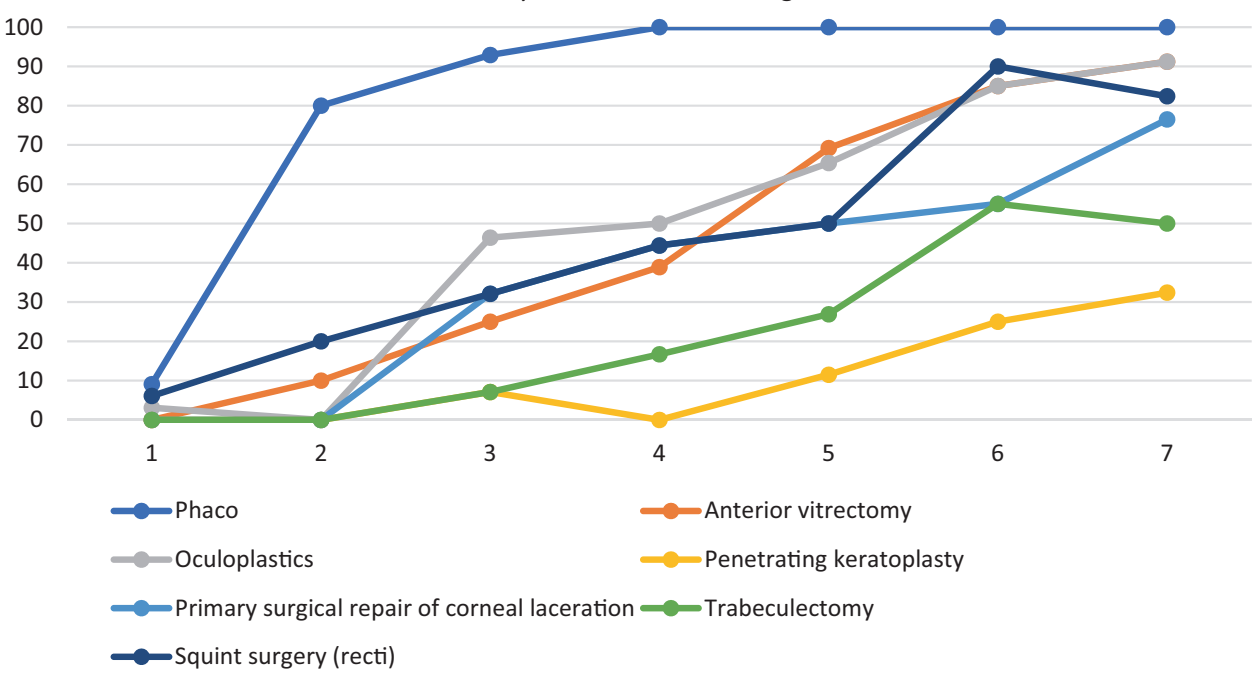


UK by sub-speciality over a 1-year period were less than the current survey proportions: oculoplastics (7\%), vitreoretinal $(5 \%)$, glaucoma $(21 \%)$ and cornea $(6 \%)$ [16]. The majority of respondents stated either clinical/surgical interest as the leading reason for their career choice; only $11.7 \%$ stated 'job opportunities' as a reason. Ophthalmology as a whole is predominantly a surgical speciality, and it is not surprising that trainees lean towards more surgical sub-specialities. Making less popular sub-specialities more attractive is a challenge, but might be addressed by focussed engagement of more trainees in British and Irish subspeciality associations, regional recruitment forums, and developing consultant job plans which offer dual subspecialisation or of a sub-speciality as part of a generalist ophthalmologist remit.

Participant trainees in this survey were not asked about changes in career choices had been made, or whether they

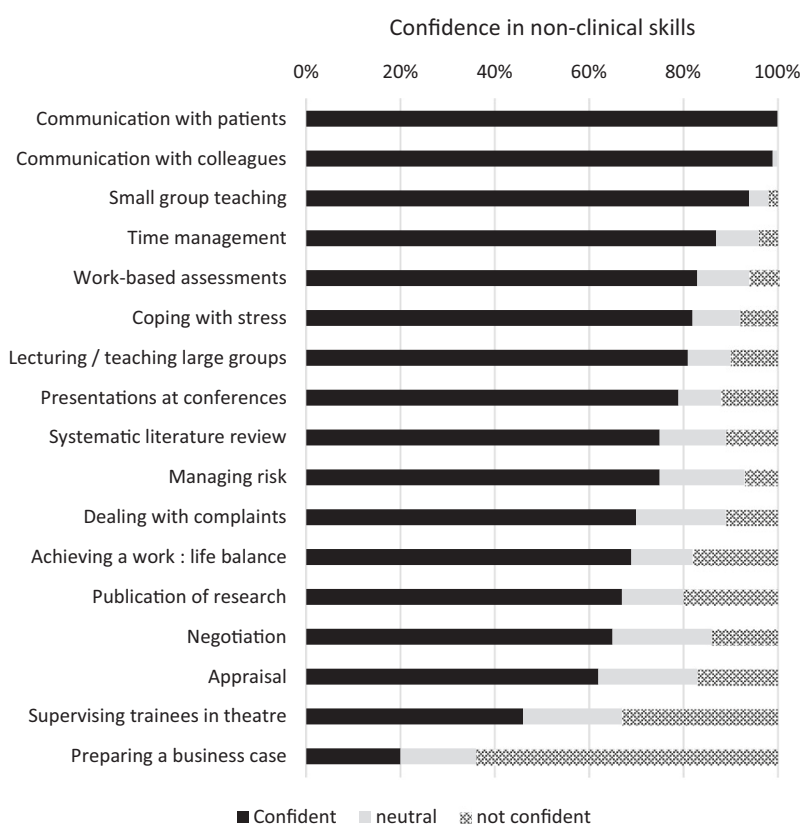

Fig. 3 Confidence in non-surgical skills would prefer to wait to choose. Four trainees did, however, comment that they were 'unsure yet' or 'undecided'. A follow-up survey could be conducted to address this question.

\section{Surgical confidence}

Training in cataract surgery occurs from the first year of ophthalmology training in the UK; trainees are expected to have completed 50 cataract operations by the end of the second year of training. This is reflected in this survey's finding that $80 \%$ of second-year trainees, and $100 \%$ of more senior specialist trainees in years 4 and above, were confident in performing phacoemulsification independently. In the United States, $16 \%$ of year-3 and $91 \%$ of year- 4 residents, and $100 \%$ of graduates felt comfortable performing phacoemulsification [9].

The Royal College of Ophthalmologists mandates that a prescribed 350 full phacoemulsification procedures must be performed by the end of the 7-year training [17], including the minimum of 50 full procedures are performed within the first 2 years of training. A retrospective review of cataract surgical experience showed that UK ophthalmologists had performed a mean of 631 (median 592) cataract surgeries by the end of training [18]. Table 2 shows prescribed surgical procedure numbers for completion of ophthalmology specialist training programmes around the world, where published data are available.

Sub-group analysis of surgical confidence in anterior vitrectomy showed that $74.4 \%$ of year 4-7 trainees (and $91.1 \%$ of year 7 trainees) felt confident, while only $11.3 \%$ of year-1 to year-3 trainees felt confident in an independent anterior vitrectomy. One out of 11 final-year trainees, about to become consultant ophthalmologists, did not feel confident in independently performing an anterior vitrectomy. One trainee stated: 'It can be difficult to gain experience of difficult cataracts - many consultants will only allow trainees to attempt easy cases under supervision, but will also expect the trainee to perform solo lists when difficult cases
Table 2 Mandatory numbers of surgical procedures in Ophthalmology Training (numbers in brackets indicate a role as assistant rather than the primary surgeon)

\begin{tabular}{llllll}
\hline & $\begin{array}{l}\text { India [27] } \\
\text { (proposed) }\end{array}$ & $\begin{array}{l}\text { South Africa } \\
{[28]}\end{array}$ & UK (RCOphth) & $\begin{array}{l}\text { USA } \\
{[29]}\end{array}$ & WACS [30] \\
\hline Cataract extraction & 80 & 300 & 350 & 86 & 60 \\
Glaucoma surgery & 10 & 10 & $(20)$ & 5 & 10 \\
Lid surgery & 20 & 40 & 40 & 28 & 40 \\
Strabismus & 20 & 20 & 20 & 10 & 3 \\
Laser & 20 & 60 & 40 Retinal 30 & 24 & 10 \\
& & $(20)$ & $(20)$ & & $(10)$ \\
Retinal detachment & $1(10)$ & 1 & 2 & & 10 \\
Enucleation/ & & & & & \\
evisceration & & & &
\end{tabular}


may well be encountered'. Overall rates for posterior capsule rupture (PCR) or vitreous loss are 1.92\% [19]. The odds ratios for different risks factors for surgical complications necessitating an anterior vitrectomy are compounded by grade and experience of the surgeon. Junior trainees are known to perform fewer high-risk cataract cases. Gaining surgical competence in anterior vitrectomy can not be achieved by placing patient safety at risk, and further strategies to address this challenge should be explored including the use of simulation-based surgical education.

Only $14.2 \%$ of respondents agreed they were confident in performing an extracapsular cataract extraction (ECCE), which makes up less than $1 \%$ of cataract procedures.

Half of final-year trainees were confident in trabeculectomy; and although The RCOphth requires trainees to perform 30 glaucoma procedures, this includes laser as well as surgery. In total, $12.4 \%$ of all trainees were confident in performing a penetrating keratoplasty independently (32.4\% of final-year trainees). UK trainees are required to assist at a minimum of six corneal graft procedures. A survey in the USA similarly showed that two-thirds of trainees felt the need for some additional training in surgical areas of glaucoma, retina and paediatric ophthalmic surgery [10].

The Shape of Training report suggested that it might be possible to shorten specialist training in the UK [20]. A minority of trainees $(34.4 \%)$ thought that ophthalmic specialist training should be shortened from the current 7-year programme. A larger minority (44.8\%) agreed when asked: 'Do you think training could be shortened, and still produce competent consultant ophthalmologists?'

Nearly one quarter $(24.5 \%)$ of respondents to this survey had opted out of the EWTD, with two trainees specifically stating the desire to do locum work as the reason. A recent study of UK ophthalmologists in training reported that $40.7 \%$ felt that their training had been adversely affected by limited hours. Nearly half $(49.1 \%)$ thought that ophthalmology trainees should opt out of the EWTR to work more than $48 \mathrm{~h}$ per week, with 57 being the mean number of hours suggested as appropriate [21]. The discrepancy between these results and the current survey may indicate that more trainees would choose to opt out of the EWTD than are currently doing so.

In the current survey, when asked, 'does your contract reflect the number of hours you actually work?': $54.8 \%$ agreed and $33.5 \%$ disagreed. This is slightly higher than the $44.4 \%$ of trainees who reported in 2013 that their posts were compliant with the EWTR [21].

\section{Non-clinical skills}

The most confidence was reported for communication with patients and with colleagues, small group teaching and presentation at conferences. This reflects the widespread opportunities to gain experience in these skills at all stages of UK ophthalmic training.

Of all the non-clinical skills, trainees felt lest confident in 'preparing a business case', with $42.0 \%$ disagreeing (or strongly disagreeing) that they felt confident in this task, and only $10.1 \%$ agreeing (or strongly agreeing). This is similar to a survey in the USA where at least $60 \%$ of trainees reported being unprepared in the non-clinical areas explored (business operations and finance, practice management, coding, advocacy and exposure to practice setting models) [10]. Canadian trainees also reported inadequate training in training in certain non-clinical areas, such as practice management, and staffing and administration skills [11]. Trainees and new consultants in other specialties in the UK have likewise reported that they felt least prepared in non-clinical areas [22-25]. Specific training could be offered by newly appointed consultants and those with business administration expertise, under The Royal College or local Deaneries, to close the skills gap in developing a business case, risk management and negotiation.

\section{Limitations of this study}

It was not appropriate to compare the results from different geographical areas due to the small number of responses received from many. There may be regional variations in training experience which this survey does not capture. Nonetheless, many training issues are best addressed at a national level, and we believe this survey provides useful data to help shape policy. We do accept that there will be variances at a regional as well as individual training institution level (often dependent on the stage of training) with different facilities, sub-specialities offering training, trainers and clinical leads. It is beyond the scope of this survey to control for these complex potential extraneous influencers, and a more detailed study would be needed.

This survey did not ask trainees about the numbers of ophthalmic procedures they had performed, which has been reported elsewhere. Instead, it was focussed on subjective confidence which tends to increase with experience but is not synonymous with proficiency.

A 4-week period was allowed for collection of responses. Although regular reminders were sent during this period, and the completion rate did fall off after 2 weeks, in retrospect a longer data collection period could have been used to increase the response rate.

\section{Conclusions}

UK ophthalmology training is long, and trainees must perform large numbers of surgical procedures. It is highly rated in comparative studies [3]. 
Two-thirds of UK trainees did not favour shortening the current training, and just under half agreed that shorter training would produce competent UK consultant ophthalmologists. This opposition to shortening a very long training period reflects the high level of competence in diverse areas of ophthalmology expected from a newly qualified UK consultant.

All senior trainees felt confident in performing independent phacoemulsification cataract surgery. Lower levels of confidence were reported in performing anterior vitrectomy or corneal laceration repair, although these are required skills for most UK consultant ophthalmologists (unlike glaucoma surgery, corneal grafts or strabismus surgery, which in the UK are increasingly performed by subspecialists rather than general ophthalmologists.) This suggests that Regional Training Programmes and The Royal College of Ophthalmologists should target resources to increase training opportunities for anterior vitrectomy and primary corneal trauma repair for UK trainees. The RCOPhth had already mandated simulated surgery in training, having published advice and a curriculum [26]. Since this survey, a Simulation Lead has been appointed to develop simulation-based surgical education courses in surgical skills. One of the Lead's first tasks is developing the materials for a course, on managing the complications of cataract surgery, to be rolled out to all regions and held at least annually. A similar plan for a course on managing primary corneal repair could be devised.

Business planning, risk management, handling complaints and supervising trainees (especially those in difficulty) are important elements of the modern consultant role and rarely delegated to trainees. Ophthalmic trainees consequently lack confidence in these areas. Short courses in leadership and management skills could be usefully supplemented by UK-wide online learning covering a range of non-clinical skills relevant to ophthalmology. Trainees would benefit from opportunities to undertake more nonclinical tasks under supervision during their training to ensure that they have real-world experience to complement the theory taught in courses.

It remains to be seen how the Shape of Training review and Britain leaving the EU will affect ophthalmology, and indeed all medical and surgical training in the UK. The former will facilitate changes to training, potentially without all ophthalmologists undertaking surgical training. Shortening training may indeed be possible, but would require more focus and resources for clinical, surgical and generic skills; and less focus on service provision, in order to produce well-rounded ophthalmologists with sufficient general skills to fulfil the requirements of the Shape review. Brexit in part may remove some of the regulations on trainee doctors' working hours.
Further iterations of the survey will help demonstrate the effects of ongoing developments in training and external factors such as Shape of Training and Brexit.

\section{Summary}

\section{What was known before}

- Ophthalmology Training in the UK is 7 years in duration, and the mean number of cataracts performed is 631 .

\section{What this study adds}

- Trainees are satisfied with UK training, are $100 \%$ confident in communication skills with patients, and $100 \%$ of senior trainees are confident in performing independent cataract surgery.

Acknowledgements The authors would like to acknowledge the members of the Ophthalmologist in Training Committee and the Training Committee of the Royal College of Ophthalmologists, UK.

\section{Compliance with ethical standards}

Conflict of interest The authors declare that they have no conflict of interest.

Publisher's note: Springer Nature remains neutral with regard to jurisdictional claims in published maps and institutional affiliations.

\section{References}

1. RCOphth. Workforce Census 2016 [https://www.rcophth.ac.uk/w p-content/uploads/2017/03/RCOphth-Workforce-Census-2016. pdf; accessed 10 June 2018].

2. Kennedy C. Specialty Training Applications for Entry in 2016: Competition Ratios and the Application Process. BMJ. 2015;351. JSTOR, https://www.jstor.org/stable/26524510.

3. GMC. Training environments 2017: key findings from the national training surveys. 2017 [https://www.gmc-uk.org/keyfindings-31410.asp?utm_source=gmcnews_doctors\&utm_ medium $=$ email\&utm_campaign $=$ ntsreport $2017 \& u t m \_$content $=$ trainee_incomplete\&dm_i $=2 \mathrm{P} 18, J O F Q, 1 T J N M, 21 X R S, 1$; accessed 27 November 2017].

4. Chesser S, Bowman K, Phillips H. The European working time directive and the training of surgeons. BMJ. 2002;325:S69.

5. Smith JA. Re: A response to European working time directive and surgical training. An open letter to the presidents of the Surgical Royal Colleges and Programme Directors of Higher Surgical Training. Response from D. Rowley, Director of Education, Royal College of Surgeons of Edinburgh. Surgeon. 2004;2:358.

6. UKHealthDepartments. The next steps - The Future Shape of Foundation, Specialist and General Practice Training 
Programmes. 2004 [http://webarchive.nationalarchives.gov.uk/ 20130107105354/http:/dh.gov.uk/prod_consum_dh/groups/dh digitalassets/@dh/@en/documents/digitalasset/dh_4079532.pdf; accessed 19 April 2017.

7. Madden GB, Madden AP. Has Modernising Medical Careers lost its way? BMJ. 2007;335:426-8. https://doi.org/10.1136/bmj. 39300.591632.DE

8. Greenway D Shape of Training: Securing the future of excellent patient care. 2013 [http://www.shapeoftraining.co.uk/static/ documents/content/Shape_of_training_FINAL_Report.pdf_ 53977887.pdf; accessed 19 April 2017].

9. Abdelfattah NS, Radwan AE, Sadda SR. Perspective of ophthalmology residents in the United States about residency programs and competency in relation to the International Council of Ophthalmology guidelines. J Curr Ophthalmol. 2016;28:146-51. https://doi.org/10.1016/j.joco.2016.06.001

10. McDonnell PJ, Kirwan TJ, Brinton GS, et al. Perceptions of recent ophthalmology residency graduates regarding preparation for practice. Ophthalmology. 2007;114:387-91.

11. Zhou AW, Noble J, Lam WC. Canadian ophthalmology residency training: an evaluation of resident satisfaction and comparison with international standards. Can J Ophthalmol. 2009;44:540-7.

12. Ayanniyi AA, Adeboye A, Ademola-Popoola DS. Ophthalmology training in Nigeria: the trainee ophthalmologists' perspective. Niger Postgrad Med J. 2007;14:94-8.

13. Al-Salem KM, Al-Sarayra FA, Abu Al-Dabaat M, et al. Ophthalmology residency training in Jordan: an evaluation of quality and comparison with international standards. Int $\mathrm{J}$ Ophthalmol. 2014;7:898-904. https://doi.org/10.3980/j.issn.2222-3959.2014. 05.28

14. Ajay K, Krishnaprasad R, Divya DS Ophthalmic surgical training in Karnataka and Southern India: Present status and future interests from a survey of final-year residents. Indian J Ophthalmol. 2015;63:306-11. https://doi.org/10.4103/0301-4738.158067

15. Young AL, Jhanji V, Liang Y, et al. A survey of perceived training differences between ophthalmology residents in Hong Kong and China. BMC Med Educ. 2015;15:158 https://doi.org/ 10.1186/s12909-015-0440-0

16. Bowes O, Dean W, Borman AD. Recent subspecialty trends in ophthalmology consultant appointments. Eye. 2017;31:164-65. https://doi.org/10.1038/eye.2016.176

17. RCOphth. Surgical skills SS4 [https://www.rcophth.ac.uk/lea rningoutcomes/ss4/; accessed 3 July 2018].
18. Hoffman J, Spencer F, Ezra D, et al. Changes in UK ophthalmology surgical training: analysis of cumulative surgical experience 2009-2015. BMJ Open. 2017;7:e018526 https://doi.org/10. 1136/bmjopen-2017-018526.

19. Narendran N, Jaycock P, Johnston RL, et al. The cataract national dataset electronic multicentre audit of 55,567 operations: risk stratification for posterior capsule rupture and vitreous loss. Eye. 2009;23:31-7. https://doi.org/10.1038/sj.eye.6703049.

20. Greenaway D. Response to the shape of training report: securing the future of excellent patient care. 2013, [http://www.shapeoftra ining.co.uk/static/documents/content/Shape_of_training_FINAL_ Report.pdf_53977887.pdf].

21. O'Gallagher MK, Lewis G, Mercieca K, et al. The impact of the European working time regulations on ophthalmic specialist training--a national trainee survey. Int J Surg. 2013;11:837-40. https://doi.org/10.1016/j.ijsu.2013.08.007.

22. Morrow G, Illing J, Redfern N, et al. Are specialist registrars fully prepared for the role of consultant? Clin Teach. 2009;6:87-90.

23. Beckett M, Hulbert D, Brown R. The new consultant survey 2005. Emerg Med J. 2006;23:461-3. https://doi.org/10.1136/emj.2005. 030726.

24. Higgins R, Gallen D, Whiteman S. Meeting the non-clinical education and training needs of new consultants. Postgrad Med J. 2005;81:519-23. https://doi.org/10.1136/pgmj.2004.028902.

25. McKinstry B, Macnicol M, Elliot K, et al. The transition from learner to provider/teacher: the learning needs of new orthopaedic consultants. BMC Med Educ. 2005;5:17 https://doi.org/10.1186/ 1472-6920-5-17.

26. RCOphth. Simulation in Training. [https://www.rcophth.ac.uk/tra ining/ost-information/simulation/; accessed 10 June 2018].

27. Dhaliwal S, Ayyala RS. Post graduate training program in ophthalmology in India: Idealistic vs realistic. J Clin Ophthalmol Res. 2015;3:39-43.

28. CMSA. Fellowship of the College of Ophthalmologists of South Africa: FC Ophth(SA) Regulations. 2017 [https://www.cmsa.co. za/view_exam.aspx?examid=28; accessed 19 April 2017].

29. ACGME. Required Minimum Number of Procedures for Graduating Residents in Ophthalmology. 2014 [https://www.acgme.org/ Portals/0/PFAssets/ProgramResources/240_Oph_Minimum Numbers.pdf; accessed 2 November 2017.

30. WACS. Training Curriculum for the Membership and Fellowship Programme. 2014 [http://www.wacscoac.org/downloads/Ophtha lmology.Curriculum.pdf; accessed 19 April 2017]. 